\title{
Female genital mutilation and skilled birth attendance among women in sub-Saharan Africa
}

Abdul-Aziz Seidu ${ }^{1,2,3^{*}}$, Richard Gyan Aboagye ${ }^{4}$, Barbara Sakyi ${ }^{5}$, Collins Adu ${ }^{6}$, Edward Kwabena Ameyaw ${ }^{7}$, Joycelyn Boatemaa Affum ${ }^{5}$ and Bright Opoku Ahinkorah ${ }^{7}$

\begin{abstract}
Background: There is evidence that women who have had their genitals cut suffer substantial difficulties during and/or after childbirth, including the need for a caesarean section, an episiotomy, an extended hospital stay, postpartum bleeding, and maternal fatalities. Whether or not women in sub-Saharan Africa who have undergone female genital mutilation utilize the services of skilled birth attendants during childbirth is unknown. Hence, we examined the association between female genital mutilation and skilled birth attendance in sub-Saharan Africa.
\end{abstract}

Methods: The data for this study were compiled from 10 sub-Saharan African countries' most recent Demographic and Health Surveys. In the end, we looked at 57,994 women between the ages of 15 and 49. The association between female genital mutilation and skilled birth attendance was investigated using both fixed and random effects models.

Results: Female genital mutilation and skilled birth attendance were found to be prevalent in $68.8 \%$ and $58.5 \%$ of women in sub-Saharan Africa, respectively. Women with a history of female genital mutilation had reduced odds of using skilled birth attendance $(\mathrm{aOR}=0.91,95 \% \mathrm{Cl}=0.86-0.96)$ than those who had not been circumcised. In Ethiopia, Guinea, Liberia, Kenya, Nigeria, Senegal, and Togo, women with female genital mutilation had reduced odds of having a trained delivery attendant compared to women in Burkina Faso.

Conclusion: This study shed light on the link between female genital mutilation and skilled birth attendance among sub-Saharan African women. The study's findings provide relevant information to government agencies dealing with gender, children, and social protection, allowing them to design specific interventions to prevent female genital mutilation, which is linked to non-use of skilled birth attendance. Also, health education which focuses on childbearing women and their partners are necessary in enhancing awareness about the significance of skilled birth attendance and the health consequences of female genital mutilation.

Keywords: Female genital mutilation, Skilled birth attendance, Sub-Saharan Africa, Women's health

*Correspondence: abdul-aziz.seidu@stu.ucc.edu.gh

${ }^{1}$ Centre for Gender and Advocacy, Takoradi Technical University, P.O.

Box 256, Takoradi, Ghana

Full list of author information is available at the end of the article

\section{Background}

Approximately 63 million girls are likely to be circumcised by 2050 [1], making it a global concern. All surgeries that entail partial or total removal of the external female genitalia for cultural reasons are included in this practise [2]. Female genital mutilation (FGM) is common in 30 African countries, with an estimated three million girls at risk of FGM each year [1, 3]. FGM is prevalent 
not just in Africa, but also in Asia and other European nations where migrants from FGM-practicing communities reside [2]. FGM is a societal phenomenon in some regions of Africa, linked to social mores and religion, and justified by the preservation of virginity, which is a requirement for marriage, initiation ceremonies, identity, conjugal fidelity, honour, purity, and increased fertility $[2,4,5]$. Many contextual factors, such as highly unequal cultures in which gender prescriptions demand girls' virginity before marriage, have been proven to reinforce FGM. The gender perspective of FGM is also rooted in the socio-cultural norm that emphasises the need for men to control women's sexuality, prevent promiscuity, ensure premarital virginity, marital fidelity and male sexual satisfaction. This is often being widely considered as a result of patriarchal oppression and the subjugation of women [6].

The World Health Organization (WHO) classifies FGM into four categories: Types 1 and 2, also known as clitoridectomy and excision, respectively, involve the partial or complete removal of the clitoris and labia, while Type 3 involves cutting and repositioning of the labia to create a partial cover and may involve stitching the tissues together (this is the most radical of all the procedures), and finally, Type 4 involves piercing or scraping of the genitalia [3]. According to the 2016 United Nations Children's Fund (UNICEF) report, around 90\% of FGM cases include either Types 1 (mainly clitoridectomy), 2 (excision), or 4 ("nicking" without flesh removed), and about $10 \%$ (over 8 million women) have gone through Type 3 (infibulation) [1].

According to a 2016 UNICEF report, Types 1 (primarily clitoridectomy), 2 (excision), and 4 ("nicking" without flesh removed) account for around $90 \%$ of FGM incidences, while Type 3 (infibulation) accounts for about $10 \%$ (about 8 million women) [1]. Infibulation, the most severe form of FGM, is predominantly practised in Djibouti, Eritrea, Ethiopia, Somalia, and Sudan in the North-Eastern area of Africa. The tendency in West Africa (Guinea, Mali, Burkina Faso, and so on) is to remove flesh (clitoridectomy and/or excision) without sewing the labia minora and/or majora together. The high prevalence of infibulation in Africa's North-East area has a negative impact on birthing [2]. High maternal mortality and FGM prevalence have long been critical concerns of public health interest in many countries in sub-Saharan Africa (SSA) [7].

The majority of high-FGM-prevalent nations also have high maternal mortality ratios and high numbers of maternal fatalities, with SSA accounting for approximately $66 \%$ of maternal deaths in 2017 [7]. The increased prevalence of maternal mortality and FGM has the opportunity to decelerate the achievement of Sustainable Development Goals 3 and 5 by 2030 .

FGM has been shown in numerous studies to be more of a disadvantage than a benefit to mutilated women. It has been linked to a variety of consequences, including extreme pain, haemorrhage, infection, cyst formation, keloids, sexual dysfunction, chronic pelvic infection, obstetric issues, and death [1-3, 8, 9]. FGM causes major difficulties during labour, including the need for a caesarean section, an episiotomy, and a protracted hospital stay, as well as post-partum bleeding and maternal fatalities [8-11]. Scar formation as a result of FGM is one of the ways in which the procedure exposes women to complications after childbirth [8]. These scars cause vaginal stenosis, in which the vaginal walls fail to gradually dilate, putting the baby's and mother's lives at danger of morbidity and mortality $[8,9]$.

Women who have experienced FGM are much more likely to encounter difficulties during childbirth and their newborns are more likely to die as a result of the procedure, according to studies on FGM and obstetric outcome in SSA $[2,10]$. This is especially true for women who have had infibulation since they are more likely to experience protracted and obstructed labour, which can lead to foetal mortality and obstetric fistula [10].

Previous research on FGM and maternal healthcare utilization (antenatal care services) found that in a nonnormative community, women who have experienced FGM may find it difficult to socialize with others [12]. It's possible that this is linked to stigma and discrimination. According to Goffman [13], stigma is a social feature that transforms a person "from a whole and ordinary person to a tainted, devalued one." As a result, physical differences caused by FGM may expose women who have already undergone it to stigma, relegating them to the status of 'other' in the greater social context, potentially preventing them from accessing public spaces. Women who have been subjected to FGM are also more likely to reject negative socio-cultural norms and practices that serve as a barrier to the utilization of maternal healthcare services, such as skilled birth attendance (SBA).

Given the difficulties associated with FGM and childbirth, circumcised women are undeniably at risk of morbidity and mortality during delivery, and this risk is exacerbated for the majority of circumcised women who deliver outside of a hospital or obstetric setting and are supervised by unskilled birth attendants [10]. Regardless, no research has been conducted to determine if women who have experienced FGM are more or less likely to use skilled birth attendants during delivery. This is significant because skilful delivery may safeguard women who have been subjected to FGM during childbirth and lower their odds of dying during the delivery process. In this regard, 
we examined the association between FGM and SBA in 10 countries in SSA, where data on FGM and other important variables considered in this study are available. This study is based on the hypothesis that women who have undergone FGM will be less likely to utilise the services of skilled birth attendants compared to those who have not undergone FGM.

\section{Methods}

\section{Study design}

The data for this study were compiled from the most recent Demographic and Health Surveys (DHS) conducted in 10 sub-Saharan African countries between 2010 and 2020 (Table 1). DHS is a globally representative and comparative survey done in over 85 low- and middle-income countries [14]. The survey is conducted by the MEASURE DHS with support from organisations within the various countries such as the statistical service and the Ministry of Health. DHS employed a crosssectional design which was carried out descriptively to collect data from the respondents. The survey used a two-stage cluster sampling technique to recruit respondents. The first stage of sampling consisted of compiling a list of primary sampling units (PSUs) or enumeration areas (EAs) that covered the entire country which was obtained from the most recent national census. The EAs were further subdivided into standardized segments of between 100-500 households each. A random sample of a predetermined segment was later chosen with a probability proportional to the size of the EA. In the second stage, households were systematically selected from a list of previously enumerated households in each selected EA segment and those who were usual residents of selected households or visitors who slept in the households on the night before the survey are interviewed. The study collected data from respondents on health indicators such

Table 1 Description of the study sample

\begin{tabular}{llcr}
\hline SN, country & Year of survey & Weighted N & Weighted \% \\
\hline 1. Burkina Faso & 2010 & 10,438 & 18.0 \\
2. Ethiopia & 2016 & 3482 & 6.0 \\
3. Guinea & 2018 & 5459 & 9.4 \\
4. Kenya & 2014 & 6674 & 11.5 \\
5. Liberia & $2019-2020$ & 3374 & 5.8 \\
6. Mali & 2018 & 3225 & 5.6 \\
7. Nigeria & 2018 & 7715 & 13.3 \\
8. Sierra Leone & 2019 & 7056 & 12.2 \\
9. Senegal & $2010-2011$ & 7105 & 12.2 \\
10. Togo & $2013-2014$ & 3466 & 6.0 \\
All countries & - & 57,994 & 100.0 \\
\hline
\end{tabular}

as mother and child health, sexual and reproductive health, domestic violence, and men's health using a crosssectional approach [14]. The data was collected from the participants using a standardised questionnaire. A recent work [15] has provided elaborate information on the DHS' sampling and data collection procedure. A total of 175,870 women aged $15-49$ years from the 10 countries were extracted for the study. Out of this, 57,994 of the women who had a childbirth history within five years prior to the survey and also had complete observations on all their corresponding variables were included in the final analysis. Thus, all the women with missing observations were dropped. In writing this paper, we followed the STROBE (Strengthening Reporting of Observational Studies in Epidemiology) reporting criteria [16]. The dataset is freely and publicly available for download at https://dhsprogram.com/data/available-datasets.cfm. All methods were performed in accordance with the Helsinki Declarations and guidelines.

\section{Variables studied Outcome variable}

SBA was considered as the outcome variable. The question "Who assisted [NAME] during delivery?" was used to analyse this variable. This was the most recent birth of the mother within the five year period prior to the survey. "Traditional Birth Attendant/Others" and "Skilled birth attendants/Health professionals" were the two responding categories. This classification and categorisation has been used in previous DHS research [17-20].

\section{Key explanatory variable}

FGM was the key explanatory variable. To obtain this variable, the respondents were asked if they had undergone FGM. "Have not undergone FGM" and "Have undergone FGM" were the response possibilities. The existing coding of the replies in the DHS datasets was retained and used in the final study and was in line with previous literature [21].

\section{Covariates}

The study included a total of 15 variables as covariates. These variables were divided into two categories: individual and contextual factors. The factors were chosen based on their availability in the DHS dataset as well as prior studies' substantial associations with SBA [17-20].

\section{Individual factors}

The individual factors included maternal age, educational level, marital status, working status, religion, antenatal care (ANC) attendance, media exposure (television, radio, and newspaper), difficulty getting permission to go to the health facility, difficulty getting money needed 
for treatment, and difficulty with distance to the health facility. We kept the existing coding for all the variables except ANC attendance, religion, and exposure to media. ANC attendance was recoded as no visit, one to three visits, and four or more visits. Christianity, Islam, African Traditional religion, No religion, and others were used to recode religion. Those who said "not at all" to radio, newspaper, or television were categorised as "not exposed [No]," whereas those who said "yes" were categorised as "exposed [Yes]." In each of the three variables, this categorisation was applied (radio, newspaper, and television).

\section{Contextual factors}

Contextual factors were wealth index, place of residence, and countries studied. We used the DHS dataset's current coding for wealth index and location of residence. The wealth index was divided into five categories: poorest, poorer, middle, richer, and richest. Residence was categorised as either "urban" or "rural." As part of the contextual factors, all of the countries investigated were taken into account.

\section{Statistical analyses}

Stata software version 16.0 was used to analyse the data (Stata Corporation, College Station, TX, USA). The analysis was carried out in three steps. To present the results of the prevalence of FGM and SBA in the first stage, percentages were employed (Fig. 1). Second, Pearson's chi-square test was used to evaluate the distribution of SBA across the explanatory variables with a p-value less than 0.05 showing statistical significance. Later, using four models, a multilevel binary logistic regression analysis was done to assess the relationship between FGM and SBA while controlling for individual and contextual characteristics. Without the explanatory variables, Model 0 indicated the variance in SBA ascribed to the clustering of the PSUs. The key explanatory variable and the individual characteristics were included in Model I. The contextual factors are included in Model II. The key explanatory variable, as well as individual and contextual factors, were included in the final model (Model III). These models were fitted using the Stata command "melogit." For model comparison, we employed Akaike's Information Criterion (AIC) tests. The fixed effect model was adopted for this study due to the complex data structure of the DHS dataset. Also, the fixed effect model took care of the variations between higher level units and lower level units within the data structure [22]. The results were presented as adjusted odds ratios (aOR) with a $95 \%$ confidence interval $(\mathrm{CI})$. To improve the generalizability of our findings, we employed sample weight (v005/1,000,000) and the 'svy' command to cater for over and under-sampling, including the complicated survey design.

\section{Ethical considerations}

Since our research was based on publicly available data, we did not seek ethical approval for this work. Ethical approval was obtained prior to the start of the survey,

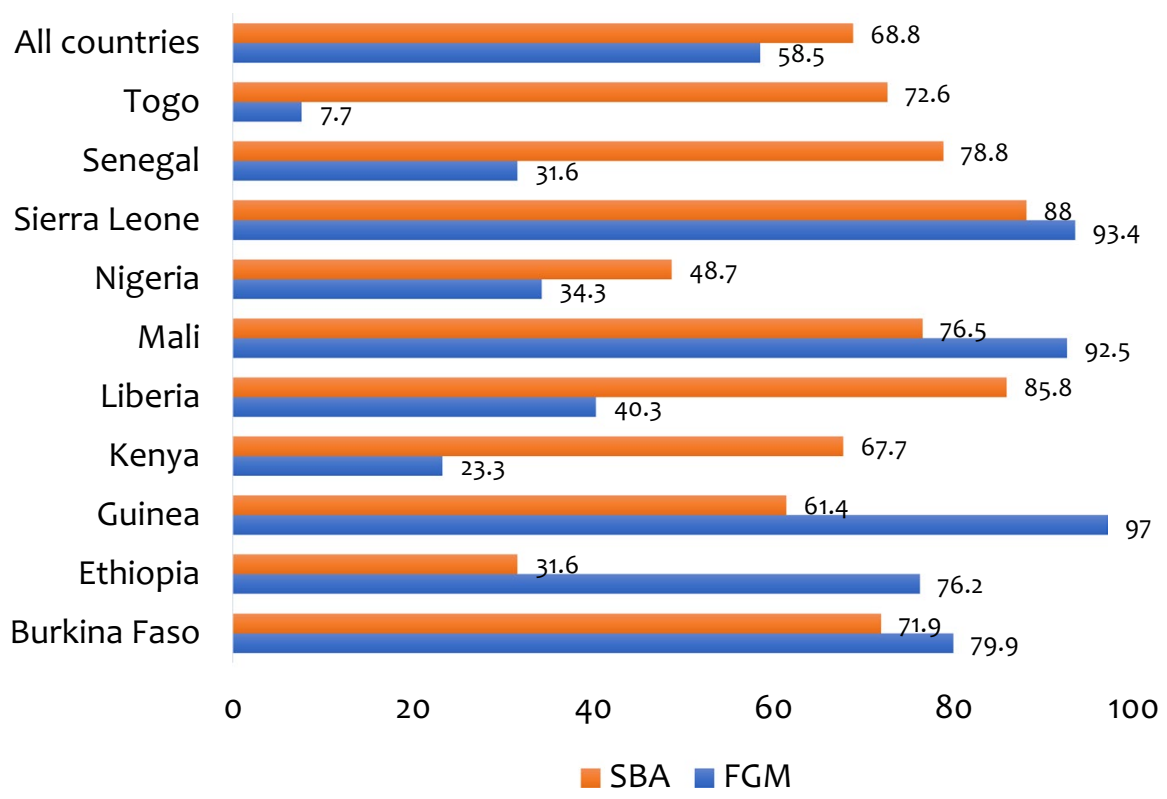

120

Fig. 1 Prevalence of FGM and SBA among women in sub-Saharan Africa 
and all ethical criteria governing the use of human participants were properly followed. Details about data and ethical standards are available at: http://goo.gl/ny8T6X.

\section{Results}

Prevalence of FGM and SBA among women in sub-Saharan Africa

The overall prevalence of FGM and SBA among women in SSA were $68.8 \%$ and $58.5 \%$ respectively. At the country level, the highest prevalence of FGM was 97\% in Guinea, with the lowest prevalence in Togo (32.5\%). On the other hand, the highest prevalence of SBA was $88 \%$ in Sierra Leone, with the lowest prevalence in Ethiopia (31.6\%) (see Fig. 1).

\section{Distribution of SBA across FGM and other characteristics of women in sub-Saharan Africa}

Table 2 presents the results on the bivariate analysis of FGM and SBA among women in SSA. The results showed a significant disparity in FGM and SBA. Specifically, SBA was less prevalent among women who had undergone FGM (67.8\%) compared to those who had never undergone FGM (70.3\%). All the covariates showed significant associations with SBA.

\section{Multilevel regression analysis of the association between FGM and SBA among women in sub-Saharan Africa}

Table 3 shows the multilevel regression analysis of the association between FGM and SBA among women in SSA. After adjusting for all covariates, we found that women who had undergone $\mathrm{FGM}(\mathrm{aOR}=0.91,95 \%$ $\mathrm{CI}=0.86-0.96)$ were less likely to utilize SBA compared to those who had not undergone FGM. At the country level, in Ethiopia, Guinea, Liberia, Kenya, and Nigeria, Senegal, and Togo, women who have had FGM had reduced odds of SBA compared to women in Burkina Faso. With the covariates, maternal age, educational level, marital status, working status, religion, ANC attendance, difficulty with permission to visit the health facility, difficulty with distance to the health facility, exposure to television and newspaper/magazine, wealth index and place of residence had significant associations with SBA.

\section{Discussion}

FGM is a social phenomenon in SSA that is linked to social mores and religion, and is justified by the preservation of virginity, which is a requirement for marriage, initiation ceremonies, identity, marital fidelity, honour, purity, increased fertility, and hygiene [2, 4, 5]. Using the most recent DHS dataset, we looked at the association between FGM and SBA among women in SSA from 2010 to 2020. The prevalence of SBA was 58.5\%, with Sierra Leone $(88 \%)$ having the highest prevalence and Ethiopia having the lowest (31.6\%). We discovered a $68.8 \%$ prevalence of FGM among women in SSA, with Guinea (97\%) having the greatest and Togo having the lowest (7.7\%). The prevalence of SBA in this study was substantially higher than in earlier studies conducted in Bangladesh (35.9\%) [23] and Nepal (48\%) [24]. Furthermore, the prevalence of FGM was higher than the $61 \%$ reported in a prior Ghanaian study [25].

Women who had undergone FGM were less likely than those who had not undergone FGM to use SBA services in this study. The stigma associated with FGM may explain this outcome, as it makes women unwilling to seek SBA services. We believe that the decreased prevalence of SBA services among women who have had FGM may be explained by perceived stigmatization in formal medical settings where there are no regulations addressing their unique SBA services, as reported by Goffman [13]. FGM typically occurs in traditional settings where the practice is widespread, but women who have had FGM may become aware of the 'otherness' of their bodies outside of these settings, which can cause discomfort and exclusion when seeking SBA services in healthcare facilities. In a previous study, women who have undergone FGM are faced with lack of specialized understanding of their health needs and also being treated by male healthcare providers may cause discomfort [26]. Other scholars have indicated that breach of privacy and confidentiality within the healthcare setting hinders FGM victims' utilisation of maternal health services of which SBA is a major component $[27,28]$. Due to the prohibition of FGM in countries in SSA such as Kenya, Nigeria, Guinea, Liberia, and Burkina Faso among others, FGM victims fear their status can cause arrest and legal actions against their relatives, hence, their preference not to seek health services including SBA $[27,28]$.

It was found that women who had 4 or more antenatal care visits had higher likelihood of obtaining SBA at birth as compared to women who had no antenatal care visits. Previous research has found similar results in Ethiopia [29], Sierra Leone, Niger, and Mali [30], Egypt [31], and Zambia [32]. It is likely because women who attend ANC are informed about the necessity of expert birth attendance. As a result, women may develop a behavioural change towards expert delivery support during their ANC follow-up.

This study also discovered residential diversity in the use of SBA. Quality services, lack of qualified personnel, poor socio-economic position, and a variety of socio-cultural norms of women may limit SBA use in rural areas compared to their urban counterparts. Longer distances to reach healthcare facilities, the expenses of maternal 
Table 2 Distribution of SBA across FGM and other characteristics of women in sub-Saharan Africa

\begin{tabular}{|c|c|c|c|c|}
\hline Variables & $\begin{array}{l}\text { Weighted } \\
\mathrm{N}\end{array}$ & $\begin{array}{l}\text { Weighted } \\
\%\end{array}$ & $\begin{array}{l}\text { SBA } \\
\text { Yes (\%) }\end{array}$ & $p$ value \\
\hline FGM status & & & & 0.005 \\
\hline Not undergone FGM & 24,056 & 41.5 & 70.3 & \\
\hline Undergone FGM & 33,938 & 58.5 & 67.8 & \\
\hline Maternal age & & & & $<0.001$ \\
\hline $15-19$ & 3941 & 6.8 & 71.1 & \\
\hline $20-24$ & 12,294 & 21.2 & 71.0 & \\
\hline $25-29$ & 15,208 & 26.2 & 70.4 & \\
\hline $30-34$ & 11,805 & 20.4 & 67.6 & \\
\hline $35-39$ & 8887 & 15.3 & 67.7 & \\
\hline $40-44$ & 4300 & 7.4 & 64.0 & \\
\hline $45-49$ & 1558 & 2.7 & 59.9 & \\
\hline Educational level & & & & $<0.001$ \\
\hline No education & 32,210 & 55.6 & 59.8 & \\
\hline Primary & 12,579 & 21.7 & 71.2 & \\
\hline Secondary & 10,985 & 18.9 & 87.2 & \\
\hline Higher & 2220 & 3.8 & 95.6 & \\
\hline Marital status & & & & $<0.001$ \\
\hline Never married & 3482 & 6.0 & 86.6 & \\
\hline Married & 48,405 & 83.5 & 66.6 & \\
\hline Cohabiting & 3581 & 6.2 & 81.1 & \\
\hline Widowed & 702 & 1.2 & 61.6 & \\
\hline Divorced & 650 & 1.1 & 67.3 & \\
\hline Separated & 1174 & 2.0 & 77.0 & \\
\hline Religion & & & & $<0.001$ \\
\hline Christianity & 20,888 & 36.0 & 74.1 & \\
\hline Islam & 34,817 & 60.0 & 66.7 & \\
\hline African Traditional & 1481 & 2.6 & 48.0 & \\
\hline No religion & 748 & 1.3 & 62.2 & \\
\hline Others & 59 & 0.1 & 53.4 & \\
\hline Current working status & & & & $<0.001$ \\
\hline No & 20,106 & 34.7 & 64.0 & \\
\hline Yes & 37,888 & 65.3 & 71.4 & \\
\hline Antenatal care attendance & & & & $<0.001$ \\
\hline None & 5664 & 9.8 & 16.5 & \\
\hline $1-3$ times & 20,240 & 34.9 & 62.9 & \\
\hline 4 or more times & 32,090 & 55.3 & 81.8 & \\
\hline Difficulty getting permission to go to the health facility & & & & $<0.001$ \\
\hline Big problem & 10,990 & 19.0 & 63.8 & \\
\hline Not a big problem & 47,004 & 81.0 & 70.0 & \\
\hline Difficulty getting money needed for treatment & & & & $<0.001$ \\
\hline Big problem & 33,278 & 57.4 & 64.3 & \\
\hline Not a big problem & 24,716 & 42.6 & 75.0 & \\
\hline Difficulty with distance to the health facility & & & & $<0.001$ \\
\hline Big problem & 21,968 & 37.9 & 57.3 & \\
\hline Not a big problem & 36,026 & 62.1 & 75.9 & \\
\hline Exposure to television & & & & $<0.001$ \\
\hline No & 34,468 & 59.4 & 58.6 & \\
\hline Yes & 23,526 & 40.6 & 83.8 & \\
\hline Exposure to radio & & & & $<0.001$ \\
\hline
\end{tabular}


Table 2 (continued)

\begin{tabular}{|c|c|c|c|c|}
\hline Variables & $\begin{array}{l}\text { Weighted } \\
\mathrm{N}\end{array}$ & $\begin{array}{l}\text { Weighted } \\
\%\end{array}$ & $\begin{array}{l}\text { SBA } \\
\text { Yes (\%) }\end{array}$ & $p$ value \\
\hline No & 21,525 & 37.1 & 59.7 & \\
\hline Yes & 36,469 & 62.9 & 74.3 & \\
\hline Exposure to newspaper/magazine & & & & $<0.001$ \\
\hline No & 51,564 & 88.9 & 66.4 & \\
\hline Yes & 6430 & 11.1 & 88.8 & \\
\hline Wealth index & & & & $<0.001$ \\
\hline Poorest & 12,075 & 20.8 & 45.2 & \\
\hline Poorer & 11,799 & 20.4 & 57.8 & \\
\hline Middle & 11,638 & 20.1 & 68.3 & \\
\hline Richer & 11,737 & 20.2 & 82.2 & \\
\hline Richest & 10,744 & 18.5 & 93.5 & \\
\hline Place of residence & & & & $<0.001$ \\
\hline Urban & 19,817 & 34.2 & 88.7 & \\
\hline Rural & 38,177 & 65.8 & 58.5 & \\
\hline
\end{tabular}

treatments, and restricted transportation options may all be challenges for rural women [17]. Women's health-promoting behaviour and access to SBA should be boosted by comprehensive community-level interventions that include residential homogeneity in relation to socioeconomic empowerment and infrastructures.

Women with a higher level of education had a higher likelihood of using SBA services than women without any formal education. Previous research in Ethiopia [33, 34], Ghana [35], Guinea-Bissau [36], and Nigeria [37] found that educational attainment was a predictor of SBA service consumption. Higher education has generally been found to be a robust predictor of maternal healthcare consumption [17, 38]. Higher education, according to Dapaah and Nachinaab [39], exposes women to health-related knowledge, which may impact their use of maternity healthcare facilities. According to research, women with some form of formal education are more receptive to innovative health-promoting ideas that support the demand side of health [39]. Several research (e.g. [40-45]) have found that well-educated women have more autonomy in making health-related decisions for themselves and their children.

Wealth index was also found to be a correlate of use of SBA in the study. When compared to their counterparts in the poorest income quintile, women in the highest wealth quintile had a higher likelihood of using maternal healthcare services such as SBA, a finding that is consistent with earlier researches conducted in diverse settings $[46,47]$. Due to a lack of financial resources, women from low-income households may prioritise basic daily necessities above healthcare services $[48,49]$. Women from wealthy families, on the other hand, may not encounter such obstacles because they have the financial means to pay for professional childbirth. Appropriate service delivery approaches are required in this context to address vulnerable impoverished women groups in society [49]. Despite the association found in all the countries, the differences in maternal and child health policy, education, cultural differences, and existing interventions may affect the results.

\section{Strengths and limitations}

The study's key strength is that it employed nationally representative datasets from the 10 sub-Saharan African countries studied. This is significant because it permits the findings to be applied to all women in the selected countries. The study also made use of sophisticated data analysis methods to ensure that the data was thoroughly examined. Apart from that, the data collection included well-trained field assistants and welldesigned questionnaires, resulting in a higher response rate. This ensures that the findings are accurate. Despite these strenghts, the study has several limitations that must be acknowledged. The first drawback is related to the research methodology used. It is worth noting that because this was a cross-sectional study, it could only reveal parameters linked to FGM and SBA among women in SSA, not established causative links. This study could have been hampered by recollection biases, which are common in DHS data. Another limitation is that 
Table 3 Mixed-effects analysis of the association between FGM and SBA among women in sub-Saharan Africa

\begin{tabular}{|c|c|c|c|c|}
\hline Variable & Model o & $\begin{array}{l}\text { Model I } \\
\text { Adjusted odds ratios [95\% } \\
\text { Cl] }\end{array}$ & $\begin{array}{l}\text { Model II } \\
\text { Adjusted odds ratios [95\% } \\
\text { Cl] }\end{array}$ & $\begin{array}{l}\text { Model III } \\
\text { Adjusted odds ratios }[95 \% \mathrm{CI}]\end{array}$ \\
\hline \multicolumn{5}{|l|}{ Fixed effect results } \\
\hline \multicolumn{5}{|l|}{$F G M$} \\
\hline Not undergone FGM & & Reference category & & Reference category \\
\hline Undergone FGM & & $1.43^{* * *}[1.36,1.49]$ & & $0.91^{* *}[0.86,0.96]$ \\
\hline \multicolumn{5}{|l|}{ Maternal age } \\
\hline $15-19$ & & Reference category & & Reference category \\
\hline $20-24$ & & $0.86,1.04]$ & & 50. $[0.81,0.99]$ \\
\hline $25-29$ & & $0.88^{* *}[0.80,0.97]$ & & $0.84^{* * *}[0.76,0.92]$ \\
\hline $30-34$ & & $0.86^{* *}[0.78,0.95]$ & & $0.81^{* * *}[0.73,0.90]$ \\
\hline $35-39$ & & $0.90 *[0.81,0.99]$ & & $0.86^{* *}[0.78,0.96]$ \\
\hline $40-44$ & & $0.85^{* *}[0.76,0.95]$ & & $0.85^{* *}[0.76,0.96]$ \\
\hline $45-49$ & & $0.81^{* *}[0.70,0.94]$ & & $0.82^{*}[0.70,0.95]$ \\
\hline \multicolumn{5}{|c|}{ Maternal educational level } \\
\hline No education & & Reference category & & Reference category \\
\hline Primary & & $1.20^{* * *}[1.13,1.27]$ & & $1.41^{* * *}[1.32,1.50]$ \\
\hline Secondary & & $2.28^{* * *}[2.11,2.47]$ & & $2.08^{* * *}[1.91,2.27]$ \\
\hline Higher & & $5.75^{* * *}[4.54,7.30]$ & & $4.68^{* * *}[3.67,5.97]$ \\
\hline \multicolumn{5}{|l|}{ Marital status } \\
\hline Never married & & Reference category & & Reference category \\
\hline Married & & $0.57^{* * *}[0.51,0.64]$ & & $0.84^{* *}[0.74,0.95]$ \\
\hline Cohabiting & & $0.79^{* *}[0.68,0.91]$ & & $0.87[0.74,1.01]$ \\
\hline Widowed & & $0.49^{* * *}[0.40,0.60]$ & & $0.72^{* *}[0.58,0.90]$ \\
\hline Divorced & & $0.49^{* * *}[0.39,0.61]$ & & $0.86[0.68,1.09]$ \\
\hline Separated & & $0.66^{* * *}[0.55,0.80]$ & & $0.84[0.69,1.03]$ \\
\hline \multicolumn{5}{|l|}{ Current working status } \\
\hline No & & Reference category & & Reference category \\
\hline Yes & & $1.30^{* * *}[1.25,1.37]$ & & $1.12^{* * *}[1.06,1.17]$ \\
\hline \multicolumn{5}{|l|}{ Religion } \\
\hline Others & & Reference category & & Reference category \\
\hline Christianity & & $3.37^{* * *}[1.68,6.77]$ & & $2.57^{*}[1.24,5.31]$ \\
\hline Islamic & & $2.96^{* *}[1.47,5.94]$ & & $1.69[0.82,3.49]$ \\
\hline African Traditional & & $2.13^{*}[1.05,4.33]$ & & $1.40[0.67,2.92]$ \\
\hline No religion & & $2.62^{* *}[1.28,5.38]$ & & $2.28^{*}[1.08,4.80]$ \\
\hline \multicolumn{5}{|c|}{ Antenatal care attendance } \\
\hline 0 & & Reference category & & Reference category \\
\hline $1-3$ & & $7.72^{* * *}[7.09,8.41]$ & & $5.52^{* * *}[5.03,6.06]$ \\
\hline 4 or more & & $16.3^{* * *}[14.98,17.77]$ & & $10.67^{* * *}[9.72,11.72]$ \\
\hline \multicolumn{5}{|c|}{ Difficulty with permission to go the health facility } \\
\hline Big problem & & Reference category & & Reference category \\
\hline Not a big problem & & $0.73^{* * *}[0.69,0.77]$ & & $0.81^{* * *}[0.76,0.86]$ \\
\hline \multicolumn{5}{|c|}{ Difficulty getting money needed for treatment } \\
\hline Big problem & & Reference category & & Reference category \\
\hline Not a big problem & & $0.96[0.92,1.01]$ & & $1.00[0.95,1.06]$ \\
\hline \multicolumn{5}{|c|}{ Difficulty with distance to health facility } \\
\hline Big problem & & Reference category & & Reference category \\
\hline Not a big problem & & $1.88^{* * *}[1.79,1.97]$ & & $1.63^{* * *}[1.55,1.72]$ \\
\hline \multicolumn{5}{|l|}{ Exposure to television } \\
\hline No & & Reference category & & Reference category \\
\hline
\end{tabular}


Table 3 (continued)

\begin{tabular}{|c|c|c|c|c|}
\hline Variable & Model o & $\begin{array}{l}\text { Model I } \\
\text { Adjusted odds ratios [95\% } \\
\text { CI] }\end{array}$ & $\begin{array}{l}\text { Model II } \\
\text { Adjusted odds ratios [95\% } \\
\text { CI] }\end{array}$ & $\begin{array}{l}\text { Model III } \\
\text { Adjusted odds ratios }[95 \% \mathrm{Cl}]\end{array}$ \\
\hline Yes & & $2.15^{* * *}[2.04,2.26]$ & & $1.35^{* * *}[1.27,1.43]$ \\
\hline \multicolumn{5}{|l|}{ Exposure to radio } \\
\hline No & & Reference category & & Reference category \\
\hline Yes & & $1.17^{* * *}[1.12,1.23]$ & & $0.99[0.94,1.04]$ \\
\hline \multicolumn{5}{|l|}{ Exposure to newspaper/magazine } \\
\hline No & & Reference category & & Reference category \\
\hline Yes & & $1.32^{* * *}[1.20,1.46]$ & & $1.32^{* * *}[1.19,1.46]$ \\
\hline \multicolumn{5}{|l|}{ Wealth index } \\
\hline Poorest & & & Reference category & Reference category \\
\hline Poorer & & & $1.80^{* * *}[1.71,1.91]$ & $1.41^{* * *}[1.33,1.50]$ \\
\hline Middle & & & $2.85^{* * *}[2.68,3.02]$ & $1.90^{* * *}[1.78,2.02]$ \\
\hline Richer & & & $5.56^{* * *}[5.17,5.99]$ & $2.89^{* * *}[2.67,3.14]$ \\
\hline Richest & & & $15.15^{* * *}[13.59,16.90]$ & $5.06^{* * *}[4.48,5.71]$ \\
\hline \multicolumn{5}{|l|}{ Place of residence } \\
\hline Urban & & & Reference category & Reference category \\
\hline Rural & & & $0.42^{* * *}[0.39,0.45]$ & $0.51^{* * *}[0.47,0.54]$ \\
\hline \multicolumn{5}{|l|}{ Countries } \\
\hline Burkina Faso & & & Reference category & Reference category \\
\hline Ethiopia & & & $0.15^{* * *}[0.14,0.17]$ & $0.17^{* * *}[0.15,0.19]$ \\
\hline Guinea & & & $0.47^{* * *}[0.43,0.51]$ & $0.52^{* * *}[0.47,0.57]$ \\
\hline Kenya & & & $0.51^{* * *}[0.46,0.55]$ & $0.20^{* * *}[0.18,0.22]$ \\
\hline Liberia & & & $2.22^{* * *}[1.98,2.47]$ & $0.76^{* * *}[0.66,0.87]$ \\
\hline Mali & & & $0.99[0.88,1.10]$ & $1.23^{* *}[1.08,1.39]$ \\
\hline Nigeria & & & $0.25^{* * *}[0.23,0.27]$ & $0.14^{* * *}[0.13,0.16]$ \\
\hline Sierra Leone & & & $3.08^{* * *}[2.81,3.38]$ & $1.63^{* * *}[1.47,1.81]$ \\
\hline Senegal & & & $1.05[0.97,1.14]$ & $0.85^{* *}[0.78,0.94]$ \\
\hline Togo & & & $0.69^{* * *}[0.62,0.76]$ & $0.39 * * * * 0.35,0.44]$ \\
\hline \multicolumn{5}{|l|}{ Random effect results } \\
\hline $\begin{array}{l}\text { Primary Sampling unit vari- } \\
\text { ance }(95 \% \mathrm{Cl})\end{array}$ & $0.739[0.655,0.834]$ & $0.559[0.488,0.640]$ & $0.368[0.319,0.425]$ & $0.252[0.214,0.296]$ \\
\hline $\begin{array}{l}\text { Intra-class correlation coef- } \\
\text { ficient }\end{array}$ & 0.183 & 0.145 & 0.101 & 0.071 \\
\hline Likelihood ratio test & $3067.99(<0.001)$ & $1644.02(<0.001)$ & $1350.75(<0.001)$ & $810.92(<0.001)$ \\
\hline Wald chi-square & Reference & $8768.67^{* * *}$ & $9256.01 * * *$ & $11,069.75^{* * *}$ \\
\hline \multicolumn{5}{|l|}{ Model fitness } \\
\hline Log-likelihood & $-35,171.908$ & $-28,535.782$ & $-28,289.52$ & $-25,531.563$ \\
\hline Akaike's Information Criterion & $70,347.82$ & $57,131.56$ & $56,611.04$ & $51,151.13$ \\
\hline Sample size & 57,994 & 57,994 & 57,994 & 57,994 \\
\hline Number of clusters & 1609 & 1609 & 1609 & 1609 \\
\hline
\end{tabular}

Exponentiated coefficients; $95 \%$ confidence intervals in brackets; Cl Confidence Interval

${ }^{*} p<0.05,{ }^{* *} p<0.01,{ }^{* * *} p<0.001$

since the data were collected at different periods, there is, therefore, the possibility of policy changes within and between these countries that could have confounded our results.

\section{Conclusion}

This study sheds light on FGM and SBA in SSA. FGM and SBA were found to be prevalent in SSA. Women with a history of FGM had reduced odds of using SBA than those who had not been circumcised. The parameters linked with FGM and skilful birth delivery in SSA 
were determined to be maternal age, marital status, exposure to television, exposure to newspapers, wealth index, place of residence, and employment status. These factors provide relevant information to government agencies working on gender, children, and social protection to help them design specific interventions to prevent FGM, which has been linked to poor reproductive health outcomes, and to increase the use of SBA. Also, health education which focuses on childbearing women and their partners are necessary in enhancing awareness about the significance of skilled birth attendance and the health consequences of FGM.

\section{Abbreviations \\ AIC: Akaike's information criterion; ANC: Antenatal care; aOR: Adjusted odds ratio; Cl: Confidence interval; COR: Crude odds ratio; DHS: Demographic and Health Survey; FGM: Female genital mutilation; PSU: Primary sampling units; SBA: Skilled birth attendance; SSA: Sub-Saharan Africa; WHO: World Health Organisation.}

\section{Acknowledgements}

We are grateful to the MEASURE DHS for granting free access to the original data.

\section{Authors' contributions}

AS, BOA and RGA conceived the study. AS, BOA, BS, RGA, CA, EA and JBA reviewed literature. BOA, RGA and AS analysed the data. All authors critically reviewed the manuscript. The authors read and amended drafts of the paper and approved the final version. AS had the final responsibility to submit for publication.

\section{Funding}

None.

\section{Availability of data and materials}

Data for this study is available at: http://dhsprogram.com/data/available-datas ets.cfm.

\section{Declarations}

Ethics approval and consent to participate

Since our research was based on publicly available data, we did not seek ethical approval for this work. Ethical approval was obtained prior to the start of the survey, and all ethical criteria governing the use of human participants were properly followed. Details about data and ethical standards are available at: http://goo.gl/ny8T6X.

\section{Consent for publication}

Not applicable.

\section{Competing interests}

The authors declare that they have no competing interests.

\footnotetext{
Author details

${ }^{1}$ Centre for Gender and Advocacy, Takoradi Technical University, P.O. Box 256, Takoradi, Ghana. ${ }^{2}$ Department of Estate Management, Takoradi Technical University, P.O. Box 256, Takoradi, Ghana. ${ }^{3}$ College of Public Health, Medical and Veterinary Sciences, James Cook University, Townsville, QLD 4811, Australia. ${ }^{4}$ Department of Family and Community Health, School of Public Health, University of Health and Allied Sciences, Ho, Ghana. ${ }^{5}$ Department of Population and Health, University of Cape Coast, Cape Coast, Ghana. ${ }^{6}$ Department of Health Promotion, Education and Disability Studies, Kwame Nkrumah University of Science and Technology, Kumasi, Ghana. ${ }^{7}$ School of Public Health, Faculty of Health, University of Technology Sydney, Sydney, Australia.
}

Received: 3 July 2021 Accepted: 21 December 2021

Published online: 30 January 2022

\section{References}

1. UNICEF. Female genital mutilation/cutting: a global concern. UNICEF; 2016.

2. United Nation Population Fund A. Women and girls, aged 15-49, who have undergone some form of FGM. United Nation Population Fund A; 2020.

3. World Health Organization. Female genital mutilation hurts women and economies. 2020. www.who.int/news-room/detail/06-02-2020-econo mic-cost-of-female-genital-mutilation.10.11

4. Akin-Tunde AO, Bosede BA, Oluwasomidoyin OB, Ayodeji SA. Female genital mutilation/cutting in Africa. Transl Androl Urol. 2017. https://doi. org/10.21037/tau.2016.12.01.

5. Ganiyu OS, Muhammad AA, Eldia D, Anam H, lan HR. Overview of female genital mutilation in Africa: are the women beneficiaries or victims? Cureus. 2020;12:e10250

6. Akweonogo P, Jackson FE, Appiah-Yeboah S, Sakeah E, Philips FJ. It's a woman's thing: gender roles sustaining the practice of female genital mutilation among the Kassena-Nankana of Northern Ghana. Reprod Health. 2021;18:52. https://doi.org/10.1186/s12978-021-01085-z.

7. WHO, UNICEF, UNFPA, World Bank Group and the United Nations Population Division. Maternal mortality: levels and trends 2000 to 2017. 2017.

8. Banks E, Meirik O, Farley T, Akande O, Bathija H, Ali M. Female genital mutilation and obstetric outcome: $\mathrm{WHO}$ collaborative prospective study in six African countries. Lancet. 2006;367:1835-41. https://doi.org/10.1016/ S0140-6736(06)688053.

9. Ismail EA. Female genital mutilation survey in Somaliland at the Edna Adan maternity and teaching hospital. Edna Adan Maternity Hospital; 2009.

10. WHO. Study group on female genital mutilation and obstetric outcome? Female genital mutilation and obstetric outcome: WHO collaborative prospective study in six African countries. Lancet. 2006;367:1835-1841.2.

11. Yasin BA, Al-Tawil NG, Shabila NP, Al-Hadithi TS. Female genital mutilation among Iraqi Kurdish women: a cross-sectional study from Erbil city. BMC Public Health. 2012;13(809):1-8.

12. Antabe R, Sano Y, Anfaara WF, Kansanga M, Chai X, Luginaah I. Antenatal care utilization and female genital mutilation in Kenya. Sex Cult. 2019;23:705-17. https://doi.org/10.1007/s12119-019-09595-6.

13. Goffman E. Stigma. Notes on the management of spoiled identity. Penguin; 1968.

14. Corsi DJ, Neuman M, Finlay JE, Subramanian S. Demographic and health surveys: a profile. Int J Epidemiol. 2012;41(6):1602-13.

15. Aliaga, A., \& Ruilin, R. Cluster optimal sample size for demographic and health surveys. Paper presented at the 7th international conference on teaching statistics-ICOTS. 2006.

16. Von Elm E, Altman DG, Egger M, Pocock SJ, Gøtzsche PC, Vandenbroucke $J P$, Initiative $S$. The strengthening the reporting of observational studies in epidemiology (STROBE) statement: guidelines for reporting observational studies. Int J Surg. 2014;12(12):1495-9.

17. Ahinkorah BO, Seidu AA, Agbaglo E, Adu C, Budu E, Hagan JEJ, Schack $T$, Yaya $S$. Determinants of antenatal care and skilled birth attendance services utilization among childbearing women in Guinea: evidence from the 2018 Guinea Demographic and Health Survey data. BMC Pregnancy Childbirth. 2021;21:2. https://doi.org/10.1186/s12884-020-03489-4.

18. Singh $P$, Singh KK, Singh $P$. Maternal health care service utilization among young married women in India, 1992-2016: trends and determinants. BMC Pregnancy Childbirth. 2021;21(1):1-3.

19. Yaya S, Zegeye B, Ahinkorah BO, Seidu AA, Ameyaw EK, Adjei NK, Shibre G. Predictors of skilled birth attendance among married women in Cameroon: further analysis of 2018 Cameroon Demographic and Health Survey. Reprod Health. 2021;18(1):1-2.

20. Rai RK, Singh PKO, Singh L. Utilization of maternal health care services among married adolescent women: insights from the Nigeria Demographic and Health Survey, 2008. Women's Health Issues. 2012;22(4):407-14. 
21. Sano Y, Konkor I, Antabe R, Ragetlie R. Physical intimate partner violence justification and female genital mutilation in Kenya: evidence from the demographic and health survey. J Aggress Maltreatment Trauma. 2021;30:1-1.

22. Bell A, Fairbrother M, Jones K. Fixed and random effects models: making an informed choice. Qual Quant. 2019;53(2):1051-74.

23. Al Kibria GM, Ghosh S, Hossen S, Barsha RA, Sharmeen A, Uddin SI. Factors affecting deliveries attended by skilled birth attendants in Bangladesh. Maternal Health Neonatol Perinatol. 2017;3(1):1-9.

24. Choulagai BP. Skilled birth attendant services in Nepal: overcoming barriers to utilization. 2017

25. Sakeah E, Debpuur C, Oduro AR, Welaga P, Aborigo R, Sakeah JK, Moyer AC. Prevalence and factors associated with female genital mutilation among women of reproductive age in the Bawku municipality and Pusiga District of northern Ghana. BMC Womens Health. 2018;18:150. https://doi.org/10.1186/s12905-018-0643-8.

26. Hess RF, Weinland JA, Saalinger NM. Knowledge of female genital cutting and experience with women who are circumcised: a survey of nurse-midwives in the United States. J Midwifery Women's Health. 2010;55(1):46-54. https://doi.org/10.1016/j.jmwh.2009.01.005.

27. Kimani S, Kabiru CW, Muteshi J, Guyo J. Exploring barriers to seeking health care among Kenyan Somali women with female genital mutilation: a qualitative study. BMC Int Health Hum Rights. 2020;20(1):1-2.

28. Mbanya VN, Terragni L, Gele AA, Diaz E, Kumar BN. Barriers to access to the Norwegian healthcare system among sub-Saharan African immigrant women exposed to female genital cutting. PLoS ONE. 2020;15(3):e0229770.

29. Ayele GS, Melku AT, Belda SS. Utilization of skilled birth attendant at birth and associated factors among women who gave birth in the last 24 months preceding the survey in Gura Dhamole Woreda, bale zone. Southeast Ethiop BMC Public Health. 2019;19(1):1-14.

30. Berg RC, Denison EA. tradition in transition: factors perpetuating and hindering the continuance of female genital mutilation/cutting (FGM/C) summarized in a systematic review. Health Care Women Int. 2013;34(10):837-95.

31. Van Rossem R, Dominique MD, Gage AJ. Women's position and attitudes towards female genital mutilation in Egypt: a secondary analysis of the Egypt demographic and health surveys 1995-2014. BMC Public Health. 2015;15:874.

32. WHO. Sexual and reproductive health: health risks of female genital mutilation (FGM). 2017. http://www.who.int/reproductivehealth/topics/ fgm/health_consequences_fgm/en/.

33. Ayele GS, Melku AT, Belda SS. Utilization of skilled birth attendant at birth and associated factors among women who gave birth in the last 24 months preceding the survey in Gura Dhamole Woreda, Bale zone, southeast Ethiopia. BMC Public Health. 2019;19:1501. https://doi.org/10. 1186/s12889-019-7818-6.

34. Mezmur M, Navaneetham K, Letamo G, Bariagaber H. Individual, household and contextual factors associated with skilled delivery care in Ethiopia: evidence from Ethiopian demographic and health surveys. PLoS ONE. 2017;12(9):e0184688. https://doi.org/10.1371/journal.pone.0184688.

35. Dickson KS, Amu H. Determinants of skilled birth attendance in the northern parts of Ghana. Adv Public Health. 2017;2017:1-8. https://doi. org/10.1155/2017/9102808.

36. Yaya S, Bishwajit G, Gunawardena N. Socioeconomic factors associated with choice of delivery place among mothers: a population-based crosssectional study in Guinea-Bissau. BMJ Glob Health. 2019;4:001341.

37. Solanke BL, Rahman SA. Multilevel analysis of factors associated with assistance during delivery in rural Nigeria: implications for reducing ruralurban inequity in skilled care at delivery. BMC Pregnancy Childbirth. 2018;18:438. https://doi.org/10.1186/s12884-018-2074-9.

38. Nyongesa C, Xu X, Hall JJ, Macharia WM, Yego F, Hall B. Factors influencing choice of skilled birth attendance at ANC: evidence from the Kenya demographic health survey. Pregnancy Childbirth. 2018;18:88. https:// doi.org/10.1186/s12884-018-1727-z.

39. Dapaah JM, Nachinaab JO. Sociocultural determinants of the utilization of maternal health care services in the Tallensi District in the Upper East Region of Ghana. Adv Public Health. 2018. https://doi.org/10.1155/2019/ 5487293.
40. Ahmed S, Creanga AA, Gillespie DG, Tsui AO. Economic status, education and empowerment: implications for maternal health service utilization in developing countries. PLoS ONE. 2010;5:11190.

41. Adhikari R. Effect of Women's autonomy on maternal health service utilization in Nepal: a cross sectional study. BMC Womens Health. 2016;16:26.

42. Corroon M, Speizer IS, Fotso J-C, Akiode A, Saad A, Calhoun L, Irani L. The role of gender empowerment on reproductive health outcomes in urban Nigeria. Matern Child Health J. 2014;18:307-15.

43. Ganle JK, Obeng B, Segbefia AY, Mwinyuri V, Yeboah JY, Baatiema L. How intra-familial decision-making affects women's access to, and use of maternal healthcare services in Ghana: a qualitative study. BMC Pregnancy Childbirth. 2015;15:173.

44. Morzaria M, Ahmed Z. Education and awareness make progress against female genital cutting in Kenya. Kenya. 2006. https://www.unicef.org/ protection/kenya_35433.html.

45. Sado L, Spaho A, Hotchkiss DR. The influence of women's empowerment on maternal health care utilization: evidence from Albania. Soc Sci Med. 2014;114:169-77.

46. Adu J, Tenkorang E, Banchani E, Allison J, Mulay S. The effects of individual and community-level factors on maternal health outcomes in Ghana. PLoS ONE. 2018;13(11):e0207942. https://doi.org/10.1371/journal.pone. 0207942.

47. Ochako R, Jean-Christophe F, Lawrence I, Anne K. Utilization of maternal health services among young women in Kenya: insights from the Kenya Demographic and Health Survey, 2003. BMC Pregnancy Childbirth. 2011;11:1.

48. Amin R, Shah NM, Becker S. Socioeconomic factors differentiating maternal and child health-seeking behavior in rural Bangladesh: a crosssectional analysis. Int J Equity Health. 2010;9:9.

49. Singh L, Rai RK, Singh PK. Assessing the utilization of maternal and child health care among married adolescent women: evidence from India. J Biosoc Sci. 2011;44:1-26.

\section{Publisher's Note}

Springer Nature remains neutral with regard to jurisdictional claims in published maps and institutional affiliations.

Ready to submit your research? Choose BMC and benefit from

- fast, convenient online submission

- thorough peer review by experienced researchers in your field

- rapid publication on acceptance

- support for research data, including large and complex data types

- gold Open Access which fosters wider collaboration and increased citations

- maximum visibility for your research: over $100 \mathrm{M}$ website views per year

At BMC, research is always in progress.

Learn more biomedcentral.com/submissions 